\title{
Atmospheric emissions and long-range transport of persistent organic chemicals
}

\author{
M. Scheringer ${ }^{\mathrm{a}}$ \\ Institute for Chemical and Bioengineering, ETH Zürich, 8093 Zürich, Switzerland
}

\begin{abstract}
Persistent organic chemicals include several groups of halogenated compounds, such as polychlorinated biphenyls (PCBs), polybrominated diphenylethers (PBDEs), and polyfluorinated carboxylic acids (PFCAs). These chemicals remain for long times (years to decades) in the environment and cycle between different media (air, water, sediment, soil, vegetation, etc.). The environmental distribution of this type of chemicals can conveniently be analyzed by multimedia models. Multimedia models consist of a set of coupled mass balance equations for the environmental media considered; they can be set up at various scales from local to global. Two applications of multimedia models to airborne chemicals are discussed in detail: the day-night cycle of PCBs measured in air near the surface, and the atmospheric long-range transport of volatile precursors of PFCAs, formation of PFCAs by oxidation of these precursors, and subsequent deposition of PFCAs to the surface in remote regions such as the Arctic.
\end{abstract}

\section{Persistent organic chemicals as multimedia chemicals}

The category of persistent organic chemicals includes substances such as polychlorinated biphenyls (PCBs), polychlorinated dibenzodioxins and -furans (PCDD/Fs), polybrominated diphenylethers (PBDEs), and polyfluorinated carboxylic acids (PFCAs) and sulfonic acids (PFSAs) [1]. The first common characteristic of these - chemically quite diverse - substances is that they are persistent in the environment, i.e. are degraded only slowly by chemical agents and microorganisms. The second important characteristic of this type of chemicals is that they cycle between different environmental media such as soil, water, sediment and air [2]. This is why they are referred to as "multimedia chemicals". The atmosphere is in most cases the dominant medium of environmental long-range transport of persistent organic chemicals, but the chemicals are not only present in the air compartment, but undergo cycles of deposition and revolatilization; their main reservoirs are in water and soil. Therefore, it is important to include all major environmental media in a conceptual description of the environmental fate of persistent organic chemicals. The term "environmental fate" refers to the interplay of (i) partitioning between different environmental compartments, such as deposition from air to soil and revolatilization back to air, (ii) chemical transformation and degradation by reaction with chemical agents such as hydroxyl radicals and by microbial transformation, and (iii) transport with moving air and also water (rivers, ocean currents).

A suitable framework for a quantitative description of the environmental fate of persistent organic chemicals are so-called multi-compartment or multimedia models [2,3]. Multimedia models are based on concepts from chemical engineering: they describe the environment as a system of coupled reservoirs and reactors. Each environmental compartment is represented by a single well-mixed volume that

\footnotetext{
a e-mail: scheringer@chem.ethz.ch
}

This is an Open Access article distributed under the terms of the Creative Commons Attribution-Noncommercial License 3.0, which permits unrestricted use, distribution, and reproduction in any noncommercial medium, provided the original work is properly cited. 
is connected to other compartments by mass-transfer processes. Within each compartment, transformation and degradation reactions can take place, depending on the chemical and/or biological activity of the compartment. In addition to this chemical and biological activity, the capacity of a compartment to absorb and store a chemical is used as a descriptor of the different environmental media in multimedia models. This capacity is described in terms of partition coefficients such as the octanol-water partition coefficient (for the relationship of chemical concentrations in soil and water) and the airwater partition coefficient or Henry's law constant (for the relationship of chemical concentrations in air and water). For each medium, a mass-balance equation is set up that describes all input and output processes. Inputs are emissions of chemical received by the medium and inflows from other media, such as volatilization from soil to air. Outputs are mass fluxes to other media, losses by chemical and biological transformation, and outflow out of the system by moving air and water, for example with water leaving a lake. If stable transformation products are formed by chemical or biological transformation processes, these transformation products can be represented by a set of separate mass-balance equations that are coupled to the mass-balance equations of the parent compound [4].

An important conceptual aspect of this modeling framework is that all mass-balance equations are formulated for the chemical(s) under consideration. Movements of air and water, in contrast, are not described by dynamic equations for air and water input to and output from a compartment, but are represented by the environmental parameters that are used as coefficients in the mass-balance equations of the chemicals. For example, wind fields describing the movement of air are represented by coefficients describing the inflow and outflow of airborne chemical in the air compartment of a multimedia model. The numerical values of these coefficients are derived from meteorological data such as the NCEP Global Climate Reanalysis data [5]. These data are then converted into rate constants (in units of 1/time) that describe the turnover of air in a grid cell.

Multimedia models based on this framework have been used for more than 30 years [6-16]. Because the framework is flexible and can be set up for smaller and larger regions, models have been presented that cover a wide range of spatial and temporal scales, from local [17] to regional [18] and global $[5,12,13]$. Because all environmental media are represented in a similar way, multimedia models have been applied to chemicals in soil [19], rivers and lakes [16,20], ocean water [21], and air. Applications to airborne chemicals are presented in the next sections.

\section{Application of multimedia models to airborne chemicals: Day-night cycle of PCBs}

A first application of the multimedia model framework to airborne chemicals deals with the day-night variability of PCB concentrations in air. In August 2007, PCB concentrations were measured in 4-h intervals at two locations in the Zürich, Switzerland [22]. The measurements were performed during a stable high-pressure system at two sites: one on a hilltop outside the city ("Uetliberg") and one in the city center; several different PCB congeners (from tri-chloro to hepta-chloro) were measured. At both sites, PCB concentrations showed a clear day-night variability, with concentration maxima during the day at the hilltop site and maxima at night at the city site. To interpret these findings, the model shown in Figure 1 was used.

For each site, the model represents the local environment of the site. In the model, the PCBs are distributed between upper air, lower air, and surface media (mainly soil and vegetation; the soil compartment also represents sealed surfaces in the city). Chemical-specific input parameters for the model are partition coefficients and degradation half-lives in air, water and soil [23,24]. Four environmental parameters describe the prevailing meteorological conditions in the model: wind speed, atmospheric mixing height, concentration of hydroxyl radicals, and temperature. For wind speed and temperature, actual values from the measurement sites were used. Values for the atmospheric mixing height were taken from the NCEP Global Reanalysis Climate data [25]; during the day, the two atmospheric layers were connected by fast exchange, which yields a mixing hight of $1500 \mathrm{~m}$, and during the night, exchange between the two layers was turned off so that the mixing height was limited to the height of the lower layer $(100 \mathrm{~m})$. At the hilltop site, measured PCB concentrations were on the order of several $10 \mathrm{pg} / \mathrm{m}^{3}$ during the day and lower at night; for this site, it was assumed that 

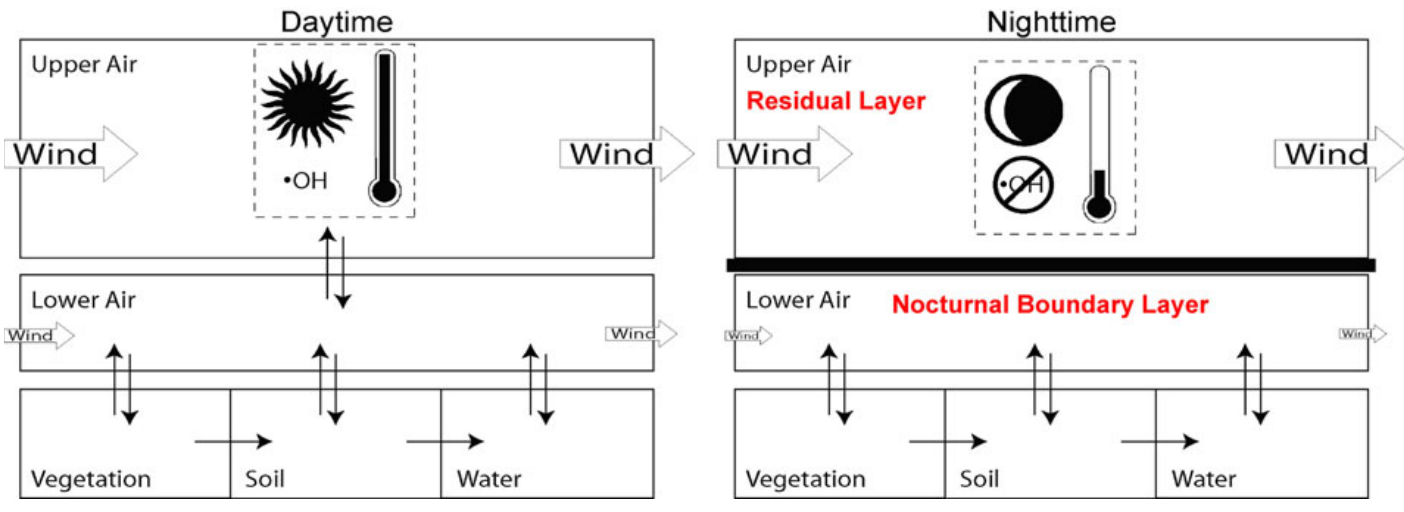

Fig. 1. Multimedia model for the local environment of PCB measurement sites in Zürich, Switzerland. The model is based on the BETR model framework [14]. Adapted with permission from MacLeod et al. [17]. Copyright 2007 American Chemical Society.

PCBs enter the model domain with inflowing air at background concentrations (on the order of several $10 \mathrm{pg} / \mathrm{m}^{3}$ ). With this set-up, the model well reproduces phase and amplitude of PCB concentrations at the hilltop site [22]; analysis of the model behavior shows that during the night PCBs are removed from the lower air compartment by increased deposition to soil and vegetation (lower vapor pressure caused by lower temperature), while there is no inflow of fresh PCBs from the upper air compartment (air compartments assumed to be separated during the night). During the day, PCBs from the upper air compartment are mixed into the lower air compartment, which causes the concentrations to rise again.

At the city site, the measured PCB concentrations were considerably higher than at the hilltop site (several $100 \mathrm{pg} / \mathrm{m}^{3}$ on average). Therefore, it was not possible to reproduce the measured levels in the model based on the assumptions that were used for the hilltop site, but an additional source of PCBs had to be assumed. This was volatilization of PCBs from the soil compartment, which was assumed to also represent building materials that may be a volatilization source of PCBs [26]. With this additional PCB source, it was possible to reproduce the PCB levels measured at the city site. The day-night dynamics of the PCB concentrations was different from that at the hilltop site: concentrations were highest during the night and lowest in the morning. According to the model, this pattern is caused by emissions into the lower air compartment that are not diluted by upward mixing during the night (air compartments separated). During the day, the volume of air available to the PCBs is larger (air compartments connected by effective mixing) and, therefore, concentrations are lower. Interestingly, this effect is stronger than the increase in PCB emissions during the day caused by higher temperatures and, accordingly, higher vapor pressures of PCBs. In other words, although emissions are stronger during the day than at night, the effect of dilution by a larger volume of air is more pronounced and causes the daytime minimum at the city site.

An important additional result from this model application to the day-night cycle of PCBs in the city of Zürich was the estimation of the PCB emission source strength. The release rate of PCBs that was needed for the modeled concentrations to match the measured levels was approximately $600 \mathrm{~kg}$ per year for the city of Zürich. This is a considerable amount and much higher than what is currently indicated by officially reported PCB emission data [27]. With the same approach, also emissions of PBDEs from the city of Zürich have been estimated; they are around $10 \mathrm{~kg} /$ year [28].

This case demonstrates that the combination of chemical concentrations measured in the environment and a multimedia model provides new insights that could not be gained from either model or measurements alone. The PCB emission estimates are a valuable piece of information that is not accessible otherwise and is necessary for the implementation of the Stockholm Convention on Persistent Organic Pollutants [1]. In addition, the model makes it possible to identify the processes governing the day-night pattern of the PCB concentrations in air. 


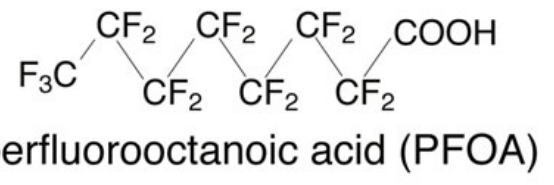

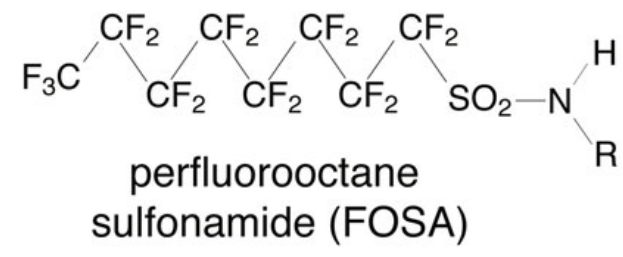

$$
\begin{gathered}
\mathrm{F}_{3} \mathrm{C} \\
\text { 8:2-fluorotelomer alcohol } \\
\mathrm{CF}_{2} \quad \mathrm{CF}_{2} \quad \mathrm{CF}_{2} \quad \mathrm{CH}_{2}-\mathrm{CH}_{2} \mathrm{OH}
\end{gathered}
$$

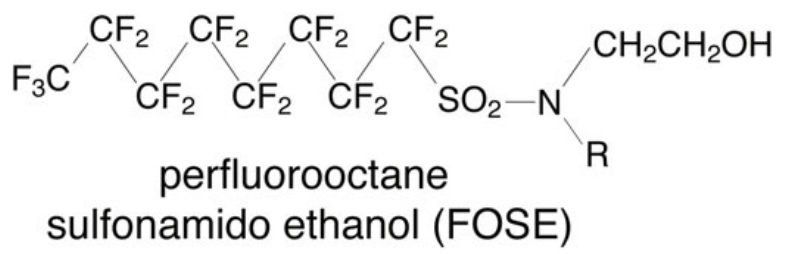

Fig. 2. Chemical structures of PFOA and selected precursor compounds. $\mathrm{R}$ : $\mathrm{CH}_{3}$, or $\mathrm{CH}_{3} \mathrm{CH}_{2}$.

\section{Application of multimedia models to airborne chemicals: Formation of perfluorooctanoic acid}

Perfluorooctanoic acid (PFOA) was extensively used as, among others, a process aid in the production of tetrafluoropolyethylene, as a component in fire-fighting foams, and is still contained as an unintended residual in fluorinated polymers that are used as impregnation materials in, for example, outdoor clothing, carpets, food contact paper and many other applications. Total emissions of PFOA to the environment in the period from 1950 to 2006 have been estimated to be around 3200-6900 tonnes [29]. PFOA is completely resistant to chemical and biological degradation in the environment and has been detected in samples from all regions of the world [30]. Because it is a relatively strong acid, PFOA released to the environment will end up in water bodies, ultimately the world's oceans. In addition to direct emissions of PFOA itself, PFOA can also be formed in the environment by oxidation of various precursors, including fluorotelomer alcohols, FTOH, and perfluorooctanesulfonamides and sulfonamido ethanols (FOSE), see Figure 2. These compounds are more volatile than PFOA and have been detected in air in many regions, mainly in the Northern hemisphere, but at lower concentrations also in the Southern hemisphere [31]. Their total contribution to PFOA in the environment is on the order of several 100 tonnes [29].

A particular source of concern is the presence of PFOA in Arctic ecosystem [32]. There are two different ways in which PFOA can be delivered to the Arctic; one is transport of PFOA present in ocean water; the other is airborne transport of FTOH and FOSE [33] in combination with oxidation of the precursors to PFOA [34,35] and subsequent deposition of PFOA to the surface media.

A record of PFOA present in inland ice of the Devon ice cap, Melville Island, Canada, has been presented by Young et al. [36]. With these data available, we investigated the hypothesis that the source of PFOA in this case is deposition from air after PFOA formation out of precursors [37]. To this end, emissions, transport and oxidation of precursors were modeled in the global multimedia model CliMoChem (Climate Zone Model for Chemicals [13]) and PFOA deposition in the Arctic region of the model was calculated. The CliMoChem model consists of a sequence of latitudinal bands; each of these bands represents a belt around the earth, see Figure 3. The purpose of this model is to investigate transport of persistent chemicals in south-north direction; the model does not have a spatial resolution in east-west direction. This structure of the model is based on the empirical finding that transport of airborne chemicals in east-west direction is considerably faster than transport in south-north direction (several days compared to several weeks). The model cannot describe single transport events, but is parameterized on the basis of long-term averages of the atmospheric circulation [38]. The model has been applied to various persistent chemicals and agreement of model results with field data was good [39-41].

The environmental parameters used in the model are based on empirical data on global distributions of temperature, concentration of hydroxyl radicals, soil organic matter, vegetation types ice and snow cover [42-48]. 


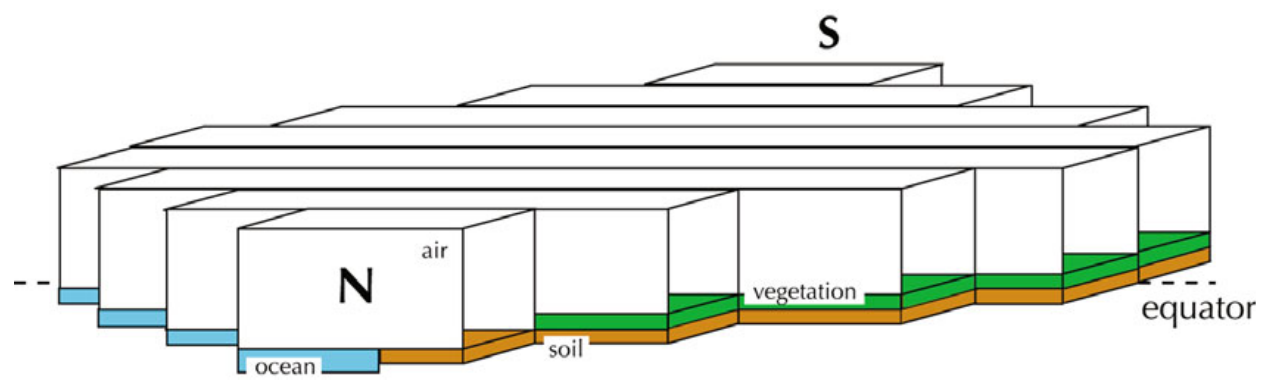

Fig. 3. Global multimedia model CliMoChem. Reprinted with permission from Scheringer et al. [13]. Copyright 2000 American Chemical Society.
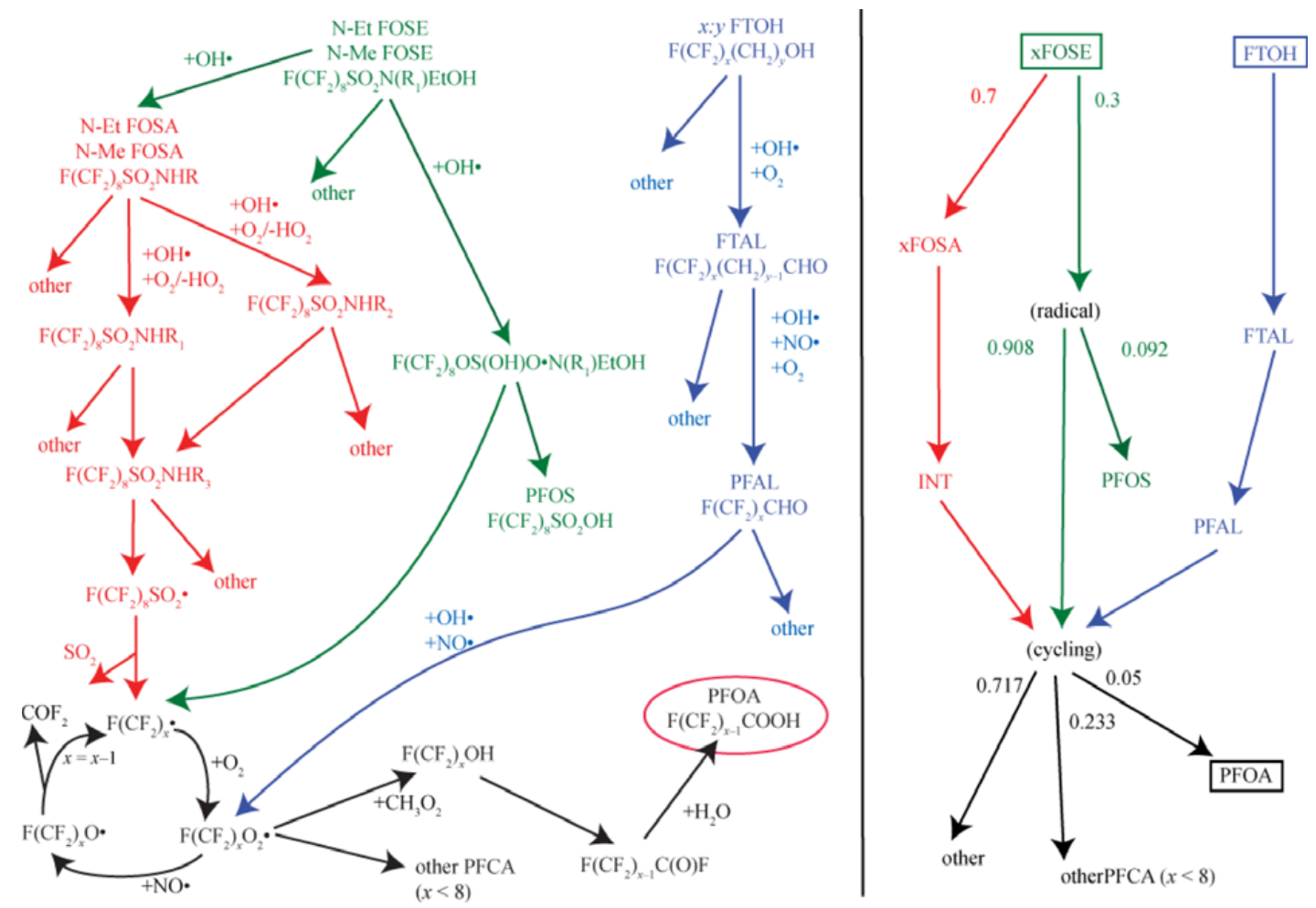

Fig. 4. Reaction scheme of PFOA precursors in air. Left: summarized information from laboratory measurements [34,35]. Right: simplified scheme implemented in the CliMoChem model; numbers indicated assumed reaction yields. Red: degradation pathways of fluorosulfonamides; green: degradation pathways of fluorosulfonamido ethanols; blue: degradation pathways of fluorotelomer alcohols; black: conversion of perfluoroalkyl radicals, $\mathrm{F}\left(\mathrm{CF}_{2}\right)_{x}$, to perfluorocarboxylic acids of different chain lengths. Reprinted with permission from Schenker et al. [37]. Copyright 2008 American Chemical Society.

To run the model for the FTOH and FOSE compounds, partition coefficients and degradation half-lives were needed. Most of these data had to be estimated from the chemical structure of the compounds or values from structurally related compounds had to be used, because almost no measured data are available for these chemicals [37]. This situation - lack of measured data for chemical properties of a substance although the substance is economically important - is frequent in the domain of industrial chemicals. In addition to the properties of the PFOA precursors, a transformation scheme describing the formation of PFOA had to be implemented in the model. This transformation scheme 


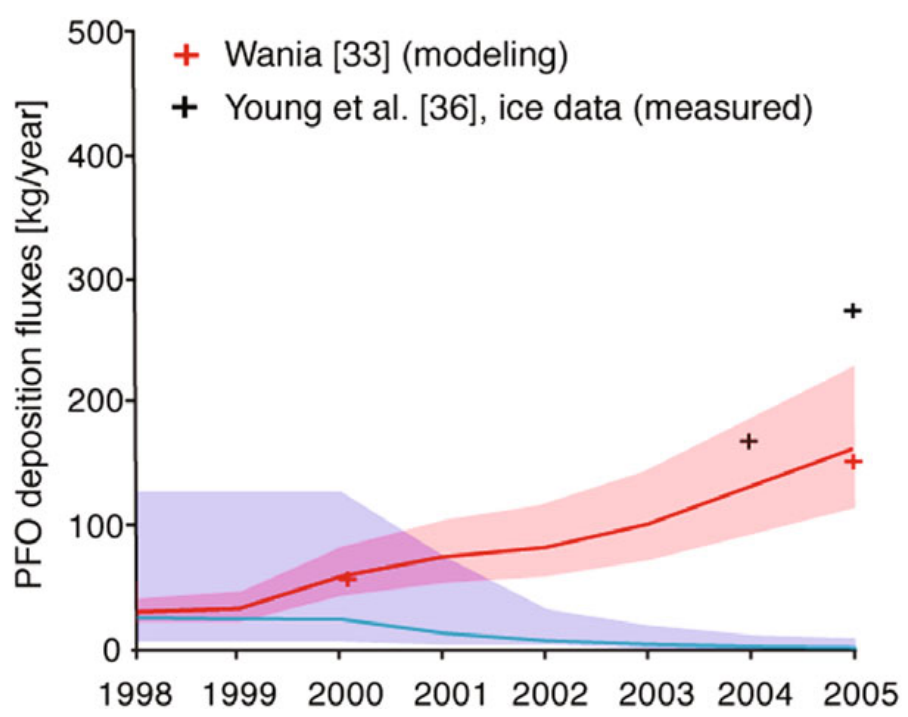

Fig. 5. Deposition of PFOA from the atmosphere to the surface north of $65^{\circ} \mathrm{N}$, in units of $\mathrm{kg} /$ year. Black: measured values [36]; red: PFOA formed by degradation of FTOH; blue: PFOA formed by degradation of FOSE. Adapted with permission from Schenker et al. [37]. Copyright 2008 American Chemical Society.

was derived from results obtained from measurements of the atmospheric oxidation of the $\mathrm{C} 4$ analogs of the C8 compounds shown in Figure $2[34,35]$. These findings for the possible reaction pathways are summarized in Figure 4, left.

Not all aspects of the empirical reaction scheme were needed for implementation in the CliMoChem model. Mechanistically, intermediate compounds that have only short half-lives are important as elements of the reaction chain but for the mass-balance calculations in the CliMoChem model, these short-lived compounds can be left out. Therefore, the simplified scheme in Figure 4, right, was implemented in the CliMoChem model. This scheme contains the overall yield of PFOA formation and those chemicals that are so long-lived that removal from the air by wet deposition is in competition with their chemical transformation. In other words, inclusion of chemicals for which transformation is much faster than deposition is not necessary for the mass budget of the formation of PFOA. Finally, data on the emission of FTOH and FOSE in the northern temperate region are needed as input to the model. These data were mainly taken from the work by Prevedouros et al. [29].

With all these prerequisites, the CliMoChem model can be run for the PFOA precursors and concentrations and deposition mass fluxes of all chemicals present in the scheme in Figure 4, right, are obtained. In these model calculations, uncertainties of chemical property data and emissions were taken into account and propagated through the model by means of Monte Carlo calculation. The model results are shown in Figure 5. PFOA formed out of FOSE is given in blue, PFOA formed out of FTOH in red; the colored bands indicate uncertainty ranges. The downward trend in the blue line reflects the assumed decrease of FOSE use from 2001 on; the red line reflects the assumed increase of FTOH emissions. The PFOA mass flux estimated with the CliMoChem model is in very good agreement with the mass flux estimated derived from measurements in ice by Young et al. [36] (black crosses). Further credibility of the model results derives from the fact that calculated FTOH concentrations in air are in good agreement with measured FTOH concentrations (data not shown).

In conclusion, application of the CliMoChem model to this case has confirmed the hypothesis that airborne precursors may cause PFOA levels observed in inland ecosystems in regions far distant from the point of release.

\section{Conclusions}

Multimedia models represent physical and chemical processes in the atmosphere only in a simplified way (parameterized wind fields, only few vertical layers, monthly or annualy average values for 
precipitation and hydroxyl radical concentrations, limitation of chemical transformation schemes to relatively long-lived compounds). The spatial and temporal resolution of the models can be adjusted in a very flexible way: if highly resolved meteorological data are available, even hourly changes and local conditions can be reflected by the models (case of PCBs in Zürich, Switzerland). If only large-scale and long-term averages of atmospheric processes and other environmental conditions are available, the models can be used at the hemispheric or global scale and provide a picture of the distribution of chemicals on these scales (PFOA case).

In all cases, multimedia models focus on the mass budget of the chemicals considered; they establish a relationship between a chemical's emissions to the environment, distribution of the chemical by air and water, transformation of the chemical into other compounds, and deposition of parent compound and transformation products to target regions. Multimedia models make it possible to identify the environmental processes that govern the observed spatial and temporal distribution pattern of a chemical. When multimedia models are combined with measured data of the chemical of interest, they provide a particularly powerful means for the interpretation of the measured trends and patterns.

\section{References}

1. Stockholm Convention on Persistent Organic Pollutants. http://www.pops.int

2. F. Wania, D. Mackay, Environ. Pollut. 100, 223-240 (1999)

3. M. MacLeod, M. Scheringer, T.E. McKone, K. Hungerbühler, Environ. Sci. Technol. 44, in press (2010)

4. K. Fenner, M. Scheringer, K. Hungerbühler, Environ. Sci. Technol. 34, 3809-3817 (2000)

5. M. MacLeod, W.J. Riley, T.E. McKone, Environ. Sci. Technol. 39, 6749-6756 (2005)

6. D. Mackay, Environ. Sci. Technol. 13, 1218-1223 (1979)

7. D. Mackay, S. Paterson, Environ. Sci. Technol. 16, 654A-660A (1982)

8. D. Rohleder, M. Matthies, J. Benz, R. Brüggemann, B. Münzer, R. Trenkle, K. Voigt, Umweltmodelle und rechnergestützte Entscheidungshilfen für die vergleichende Bewertung und Prioritätensetzung bei Umweltchemikalien (GSF, München, 1986)

9. T.E. McKone, K.G. Enoch KG, CalTOX, A Multimedia Total Exposure Model Spreadsheet User's Guide, Version 4.0. LBNL-47399 (Lawrence Berkeley National Laboratory, University of California, Berkley, CA, USA, 2002)

10. L.J. Brandes, H. den Hollander, D. van de Meent, SimpleBox 2.0: A nested multimedia fate model for evaluating the environmental fate of chemicals. RIVM Report 719101029 (National Institute of Public Health and the Environment, Bilthoven, The Netherlands, 1996)

11. D.H. Bennett, T.E. McKone, M. Matthies, W.E. Kastenberg, Environ. Sci. Technol. 32, 4023-4030 (1998)

12. F. Wania, D. Mackay, Sci. Total. Environ. 160/161, 211-232 (1995)

13. M. Scheringer, F. Wegmann, K. Fenner, K. Hungerbühler, Environ. Sci. Technol. 34, 1842-1850 (2000)

14. M. MacLeod, D.G. Woodfine, D. Mackay, T.E. McKone, D.H. Bennett, R. Maddalena, Environ. Sci. Pollut. Res. 8, 156-163 (2001)

15. N. Suzuki, K. Murasawa, T. Sakura, K. Nansai, K. Matsuhashi, Y. Moriguchi, K. Tanabe, O. Nakasuki, M. Morita, Environ. Sci. Technol. 38, 5682-5693 (2004)

16. S.A. Blaser, M. Scheringer, M. MacLeod, K. Hungerbühler, Sci. Total Environ. 390, 396-409 (2008)

17. M. MacLeod, M. Scheringer, H. Podey, K.C. Jones, K. Hungerbühler, Environ. Sci. Technol. 41, 3249-3253 (2007)

18. F. Wania, K. Breivik, N. Johan-Persson, M. McLachlan, Environ. Modell. Softw. 21, 868-884 (2006).

19. T.E. McKone, Reliab. Eng. Syst. Safe. 54, 165-181 (1996)

20. C. Bogdal, M. Scheringer, P. Schmid, M. Bläuenstein, M. Kohler, K. Hungerbühler, Sci. Total Environ. 408, 3654-3663 (2010)

21. J.M. Armitage, M. MacLeod, I.T. Cousins, Environ. Sci. Technol. 43, 1134-1140 (2009) 
22. B. Gasic, C. Moeckel, M. MacLeod, J. Brunner, M. Scheringer, K.C. Jones, K. Hungerbühler, Environ. Sci. Technol., 43, 769-776 (2009)

23. U. Schenker, M. MacLeod, M. Scheringer, K. Hungerbühler, Environ. Sci. Technol. 39, 8434$8441(2005)$

24. P.N. Anderson, R.A. Hites, Environ. Sci. Technol. 30, 1756-1763 (1996)

25. R. Kistler, E. Kalnay, W. Collins, S. Saha, G. White, J. Woollen, M. Chelliah, W. Ebisuzaki, M. Kanamitsu, V. Kousky, H. van den Dool, R. Jenne, M. Fiorino, Bull. Am. Meteorol. Soc. 82, 247-267 (2001)

26. M. Kohler, J. Tremp, M. Zenneg, C. Seiler, S. Minder-Kohler, M. Beck, P. Lienemann, L. Wegmann, P. Schmid, Environ. Sci. Technol. 39, 1967-1973 (2005)

27. European Monitoring and Evaluation Programme (EMEP), Centre on Emission Inventories and Projections (http://www.ceip.at, 2010)

28. C. Moeckel, B. Gasic, M. MacLeod, M. Scheringer, K.C. Jones, K. Hungerbühler, Environ. Sci. Technol. 44, 4225-4231 (2010)

29. K. Prevedouros, I.T. Cousins, R.C. Buck, S.H. Korzeniowski, Environ. Sci. Technol. 40, $32-44$ (2006)

30. J.P. Giesy, K. Kannan, Environ. Sci. Technol. 35, 1339-1342 (2001)

31. A. Dreyer, I. Weinberg, C. Temme, R. Ebinghaus, Environ. Sci. Technol. 43, 6507-6514 (2009)

32. R. Renner, Environ. Sci. Technol. 41, 3394-3395 (2007)

33. F. Wania, Environ. Sci.Technol. 41, 4529-4535 (2007)

34. J.C. D’Eon, M.D. Hurley, T.J. Wallington, S.A. Mabury, Environ. Sci. Technol. 40, 1862-1868 (2006)

35. J.W. Martin, D.A. Ellis, S.A. Mabury, M.D. Hurley, T.J. Wallington, Environ. Sci. Technol. 40, 864-872 (2006)

36. C. Young, V.I. Furdui, J. Franklin, R.M. Koerner, D.C.G. Muir, S.A. Mabury, Environ. Sci. Technol. 41, 3455-3461 (2007)

37. U. Schenker, M. Scheringer, M. MacLeod, J.W. Martin, I.T. Cousins, K. Hungerbühler, Environ. Sci. Technol. 42, 3710-3716 (2008)

38. C.D. Keeling, M. Heimann, J. Geophys. Res. 91 D7, 7782-7796 (1986)

39. U. Schenker, M. Scheringer, K. Hungerbühler, Environ. Sci. Technol. 42, 1178-1184 (2008)

40. U. Schenker, M. Scheringer, M.D. Sohn, R.L. Maddalena, T.E. McKone, K. Hungerbühler, Environ. Sci. Technol. 43, 128-134 (2009)

41. C. Götz, M. Scheringer, M. MacLeod, F. Wegmann, U. Schenker, K. Hungerbühler, Environ. Sci. Technol 42, 3690-3696 (2008)

42. D.R. Legates, C. Willmott, Theoret. Appl. Climatol. 41, 11-21 (1990)

43. R. DeFries, J.R.G. Townsend, Int. J. Remote Sensing 15, 3567-3586 (1994)

44. S.N. Meijer, E. Steinnes, W.A. Ockenden, K.C. Jones, Environ. Sci. Technol. 36, 2146-2153 (2002)

45. F. Wegmann, M. Scheringer, M. Möller, K. Hungerbühler, Environ. Sci. Technol. 38, 1505-1512 (2004)

46. C.M. Spivakovsky, J.A. Logan, S.A. Montzka, Y.J. Balkanski, M. Foreman-Fowler, D.B.A. Jones, L.W. Horowitz, A.C. Fusco, C.A.M. Brenninkmeijer, M.J. Prather, S.C. Wofsy, M.B. McElroy, J. Geophys. Res. 105, 8931-8980 (2000)

47. A.T.C. Chang, J.L. Foster, D.K. Hall, Ann. Glaciol. 9, 39-44 (1987)

48. J. Stocker, M. Scheringer, F. Wegmann, K. Hungerbühler, Environ. Sci. Technol. 41, 6192-6198 (2007) 